\title{
Oligomannose-Coated Liposome as a Novel Adjuvant for the Induction of Cellular Immune Responses to Control Disease Status
}

\author{
Naoya Kojima, Mariko Ishii, Yoko Kawauchi, and Hideaki Takagi \\ Department of Applied Biochemistry, Tokai University, Hiratsuka, Kanagawa 259-1292, Japan \\ Correspondence should be addressed to Naoya Kojima; naoyaki@keyaki.cc.u-tokai.ac.jp
}

Received 20 June 2013; Accepted 3 September 2013

Academic Editor: Mohammad Owais

Copyright (C) 2013 Naoya Kojima et al. This is an open access article distributed under the Creative Commons Attribution License, which permits unrestricted use, distribution, and reproduction in any medium, provided the original work is properly cited.

\begin{abstract}
Professional phagocytic cells, such as dendritic cells, are mainly responsible for phagocytosis, antigen presentation, and cytokine secretion, which induce subsequent activation of $\mathrm{T}$ cell-mediated immunity. Thus, strategies that deliver antigens and stimulatory signals to the cells have significant implications for vaccine design. In this paper, we summarize the potential for liposomes coated with the neoglycolipids containing oligomannose residues (OMLs) as a novel adjuvant for induction of Thl immune responses and CTLs specific for the encased antigen. OMLs preferentially take up peripheral phagocytic cells. In response to OML uptake, the cells secrete IL-12 selectively, enhance the expression of costimulatory molecules, and migrate into lymphoid tissues from peripheral tissues. OMLs also have the ability to deliver encapsulated protein antigens to the MHC class I and class II pathways to generate antigen-specific CTLs and Th1 cells, respectively, and lipid antigen to CD1d to activate NKT cells. Since administration of OMLbased vaccines can eliminate an established tumor, inhibit elevation of the serum IgE level, and prevent progression of protozoan infections in several murine, human, and bovine models, OML-based vaccines have revealed their potential for clinical use in vaccination for a variety of diseases in which CTLs and/or Th1 cells act as effector cells.
\end{abstract}

\section{Introduction}

The initial recognition and phagocytosis of pathogens by professional phagocytic cells, such as dendritic cells (DCs) and macrophages, and subsequent antigen presentation are crucial in determining the type of effector T cells that mediate immune responses [1-3]. Thus, targeting and functional control of these phagocytic cells is a major objective in the design of antigen delivery systems for new vaccines [4-6]. Several criteria should be fulfilled by an antigen delivery system for a vaccine to induce optimal antidisease immune responses [6]. First, specific targeting of the phagocytic cells is required. Second, delivery of the antigen to MHC class I molecules is needed to induce CTLs, and the vector must also deliver stimulatory signals to antigen presenting cells (APCs), since antigen delivery to APCs without these signals can induce tolerance. Finally, the delivery system must also be able to accommodate the insertion of large antigenic sequences to enable broad MHC coverage.
So far, many cell surface molecules expressed on APCs have been examined to target and deliver antigens to APCs in vivo. One approach to facilitate the uptake and processing of exogenous soluble antigens has been to deliver antigens via immune complexes directed to receptors for $\operatorname{IgG}(\mathrm{Fc} \gamma \mathrm{Rs})$ expressed on DCs, such as Fc $\gamma$ RI, Fc $\gamma$ RIIa, and Fc $\gamma$ RIII [7-9]. Ligands for $\alpha \mathrm{M} \beta 2$ integrin (CD11b/CD18) have also been tested for antigen delivery to APCs [10]. Alternatively, antigens can be targeted to members of the C-type lectin family expressed on DCs, such as DC-SIGN, DEC-205, LOX1, dectin-1, and the mannose receptor (CD206) [11]. Using protein antigens conjugated to antibodies directed to these APC-specific molecules, in vivo targeting approaches have produced effective results. However, promising achievement depends on overcoming the weak immunogenicity of many antigens.

On the other hand, development of particulate adjuvants and vaccines has increased during the past 30 years [4]. This has been invoked by the fact that all pathogens are particulate 
and that microparticles such as liposomes and polymer particles are efficiently uptaken by professional phagocytic cells. In addition, some of the particulate formulations tested were shown to have the potential for inducing helper and cytotoxic $\mathrm{T}$ cell responses [12]. Liposomes are vesicles formed from phospholipid bilayers and can encapsulate hydrophilic large antigenic sequences and immunomodulatory factors into the internal space of the vesicles, while amphiphilic antigens can be inserted into the bilayer and thus can serve as potent delivery vehicles [13-15]. Many types of liposomes have been tested in attempts to increase immune responses [15-17]. Enhanced uptake of liposomes by phagocytic cells indicates an adjuvant effect in inducing cellular immune responses, including the generation of antigen-specific CTLs [18, 19]. Cationic liposomes provide an important example of cellular delivery, since the positive charge on the liposome surface enhances uptake and subsequent CTL generation. Preferential delivery of antigen-containing liposomes to phagocytic cells can be facilitated by agents that bind selectively to molecular structures on the surface of the targeted cells. Conjugation of liposomes with antibodies and recombinant proteins, such as soluble forms of cell surface receptors or their ligands, can be used to target liposomes to receptors on cells $[15,20,21]$. Since C-type lectins expressed on APCs recognize certain structures of carbohydrates, such carbohydrates are also candidates for conjugation of liposomes to target APCs.

We have developed a new liposome-based antigen delivery system for control of diseases in which CTLs and/or Th1 cells act as effector cells, using oligomannose-coated liposomes (OMLs) as a novel adjuvant and antigen delivery agent [22-25]. Feasibility studies of OML-based vaccines have revealed their potential for clinical use in vaccination for diseases in which CTLs and/or Th1 cells act as effector cells. This paper provides an overview of the current progress of the OML-based vaccine.

\section{Carbohydrate-Coated Liposomes Are Suitable for Delivery of Antigens to Phagocytic Cells}

The recognition and phagocytosis of pathogens and their subsequent destruction are an important mechanism of immune defense. Pathogens share similar structures that are known as pathogen-associated molecular patterns (PAMPs). Pattern recognition receptors (PRRs), such as Toll-like receptors (TLRs) and C-type lectin receptors (CLRs), are involved in the recognition of pathogens for the induction of immune responses [26-28]. Among them, CLRs are particularly important for the recognition and uptake of glycosylated antigens, including pathogens, into cellular compartments of APCs, such as DCs, leading to processing and presentation of antigens on MHC class I and class II molecules [29, 30]. Therefore, CLRs on phagocytic cells are often called endocytic/phagocytic receptors or antigen-uptake receptors. In addition, some CLRs directly or indirectly trigger distinct signaling pathways that induce expression of specific cytokines, which then determine $\mathrm{T}$ cell polarization [31]. The abilities of CLRs to mediate endocytosis and intracellular sorting of ligands and to trigger intracellular signaling implicate that CLRs are potentially useful for antigen targeting. Antibodymediated targeting to APC-restricted CLRs, such as CD206, DEC-205, DC-SIGN, dectin-1, dectin-2, and DNGR-1, can be used to deliver antigens to late endosomal-lysosomal compartments of APCs, followed by the generation of MHC complexes of antigenic peptides to induce antigen-specific $\mathrm{CD}^{+}$and/or $\mathrm{CD}^{+} \mathrm{T}$ cell responses [32-34]. However, targeting of CLRs with these antibodies cannot deliver stimulatory signals to APCs, and therefore, an additional adjuvant is required for the maturation and activation of APCs [34]. Since CLRs recognize distinct carbohydrates expressed on pathogens, the use of carbohydrates that are preferentially recognized by CLRs as targeting signals may provide a more sophisticated alternative, and carbohydrate-coated liposomes with encapsulated antigens may be a more suitable antigen delivery vehicle to target CLRs than antibodies.

\section{Oligomannose-Coated Liposomes Are Preferentially Ingested by Phagocytic Cells In Vivo}

Carbohydrate structures containing terminal mannose are aberrant components of the cell surface of living mammalian cells. On the other hand, such structures are abundant and highly conserved on the surface of many pathogens. The professional phagocytic cells express a number of CLRs with an EPN motif in their carbohydrate recognition domain [30]. These CLRs facilitate the binding and uptake of ligands with terminal mannose, fucose, and $N$-acetylglucosamine residues and are thought to participate in the capture of pathogens $[25,35]$. This activity was first observed for the CD206 but has now been focused on the family of DC-SIGN (CD209), Langerin (CD207), and dectin-2, since expression of these CLRs is restricted to professional phagocytic cells, such as immature DCs and macrophages [36-39]. These CLRs, which are restricted to phagocytic cells, are thought to be targets for specific antigen delivery. It has been shown that antigens modified by mannose residues can be preferentially delivered into APCs via CD206- or CD209-mediated uptake of antigens, resulting in effective antigen presentation to $\mathrm{T}$ cells [40]. These results led us to predict that antigencarrying liposomes coated with mannose residues would induce strong immune responses in vivo. There are several examples in the literature of the use of liposomes decorated with mannose or mannan to target the mannose receptors on DCs [41-43], but the majority of studies have only been performed in vitro.

For in vivo targeting of APCs, we used OMLs comprised of dipalmitoylphosphatidylcholine (DPPC), cholesterol, and a neoglycolipid containing oligomannose residue at a 10:10:1 molar ratio. The oligomannose-containing neoglycolipid was prepared by conjugation of mannotriose (Man3) or mannopentaose (Man5) with dipalmitoylphosphatidylethanolamine (DPPE) by reductive amination [24]. The purities of the neoglycolipids were at least 95\%. Neoglycolipid-coated liposomes consisting of cholesterol, DPPC, 

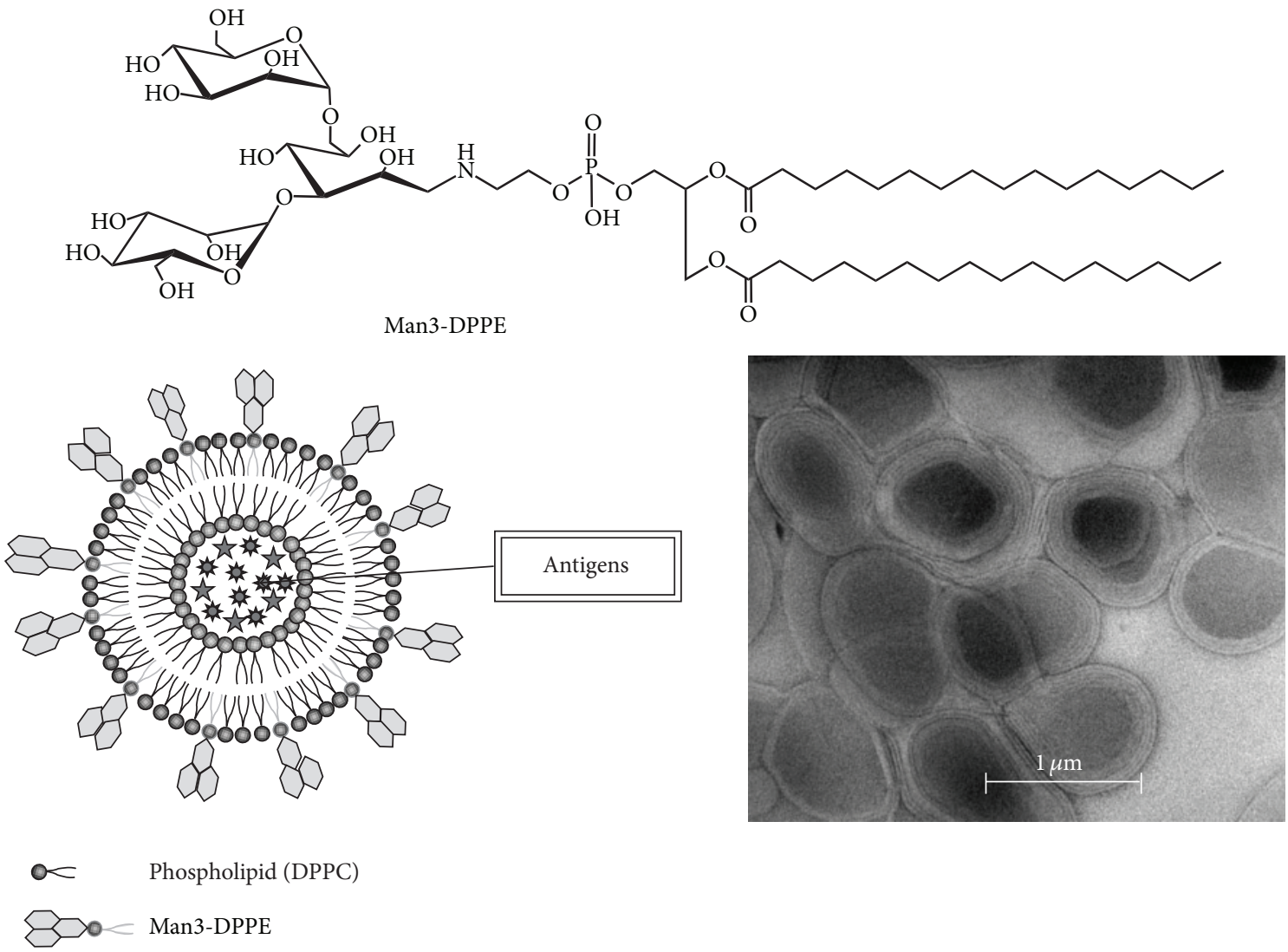

Oligomannose-coated liposomes (OMLs)

Figure 1: Representation of an OML. Man3-DPPE was prepared by reductive amination of an aldehyde group at the end of the mannotriose (Man3) with an amino group of DPPE. OMLs are prepared from DPPC, cholesterol, and Man3-DPPE at a molar ratio of $10: 10: 1$ by intense vortex dispersion with antigen-containing PBS and are extruded through a $1 \mu \mathrm{m}$ pore membrane.

and a neoglycolipid were prepared as follows. A chloroformmethanol $(1: 1, \mathrm{v} / \mathrm{v})$ solution containing $1.5 \mu \mathrm{mol}$ of DPPC, $1.5 \mu \mathrm{mol}$ of cholesterol, and $0.15 \mu \mathrm{mol}$ of neoglycolipid was added to a flask and evaporated to prepare a lipid film containing neoglycolipid. PBS $(150 \mu \mathrm{L})$ containing antigens was added to the dried lipid film and multilamellar vesicles were prepared by intense vortex dispersion. The vesicles were extruded 10 times through a $1 \mu \mathrm{m}$ pore polycarbonate membrane [24]. The mean $( \pm$ SD) molar ratio of DPPC, cholesterol, and neoglycolipid in the liposomes was 1.00:1.09 \pm $0.21: 0.11 \pm 0.03$, and the particle sizes of the liposomes ranged from about 850 to $1450 \mathrm{~nm}$, with a mean of $1265 \mathrm{~nm}$. As shown in Figure 1, the hydrophobic moiety of the neoglycolipid permits easy incorporation into the lipid bilayer of multilamellar vesicles (liposomes) comprised of DPPC and cholesterol. On the other hand, the carbohydrate moieties of neoglycolipids on OMLs are exposed on the aqueous face due to their hydrophilicity, since OMLs aggregate with concanavalin $\mathrm{A}$, a mannose-binding lectin. This also indicates that OMLs could be used in targeting mannose-recognizing molecules, such as CD206 and CD209, which are expressed on APCs in vivo. It should be noted that the structures of Man3 and Man5 are part of high mannose-type Nlinked oligosaccharides, which are ubiquitously present in eukaryotic cells, and the other components of OMLs are also ubiquitously distributed inert materials. Therefore, OMLs do not exhibit antigenicity, probably due to their recognition as "self" or "harmless foreign" particles.

Initial evidence supporting the hypothesis that OMLs could be used as delivery vehicles targeted to phagocytic cells in vivo was based on preferential uptake of FITC-BSA encasing OMLs (FITC-OMLs) by peritoneal phagocytic cells. Most of $\mathrm{CD}_{11 b^{+}}$peritoneal phagocytic cells took up FITC-OMLs within $1 \mathrm{~h}$ after injection of the OMLs into the peritoneal cavity of mice (Figure 2), and the FITC-OML-containing cells subsequently appeared in extranodal lymphoid tissues within $24 \mathrm{~h}$ [44]. In addition, the ingested FITC-OMLs also appeared in late endosomes and lysosomes. On the other hand, FITCBSA encased by liposomes without a neoglycolipid coating (FITC-BLs) was barely ingested by the peritoneal phagocytic cells. Comparison of the uptake efficiencies of FITC-OMLs and FITC-BLs, based on intensities of fluorescent signals, showed that the peritoneal phagocytic cells took up FITCOMLs at least 15 -fold more effectively than FITC-BLs. FITCOMLs but not FITC-BLs also accumulated into the draining lymph nodes following subcutaneous administration. These results strongly indicated that OMLs could act as a suitable vehicle for in vivo targeting of APCs. 


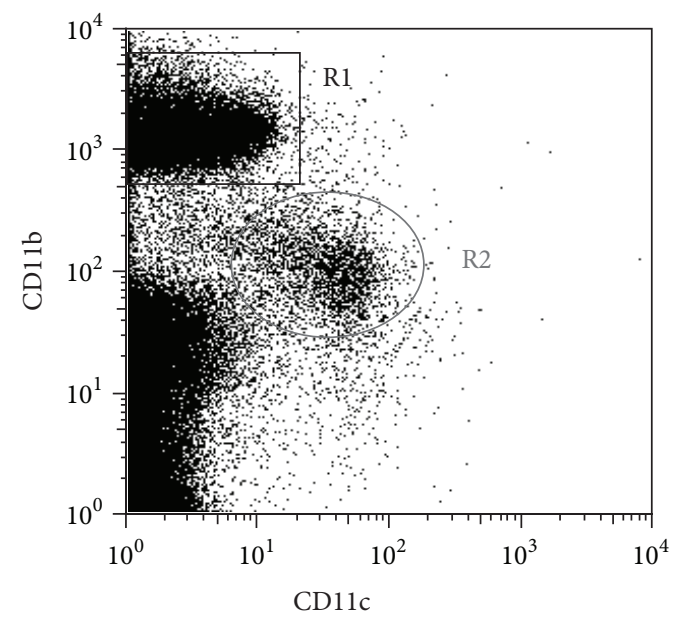

Figure 2: Uptake of OMLs by peritoneal phagocytic cells. Peritoneal phagocytic cells are classified into CD11b ${ }^{+} \mathrm{CD} 11 \mathrm{c}^{-}(\mathrm{R} 1)$ and

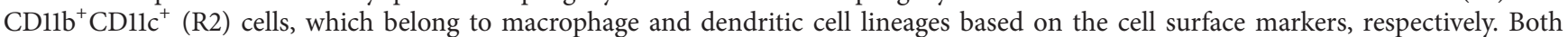
macrophage and DC-like cells effectively took up OMLs, when OMLs were administrated into peritoneal cavity.

SIGNR1 (CD209b), a mouse homologue of human DCSIGN, participates in intraperitoneal uptake of OMLs by peritoneal phagocytic cells [45]. In addition, complement receptor 3 (CR3; CD11b/CD18) also acts as the physiological receptor of OMLs [46]. Recently, it has been reported that C3 deposition on microorganisms is initiated by the interactions of SIGNR1 with polysaccharides on the microorganism and the complement $\mathrm{C} 1$ subcomponent, followed by activation of the classical complement pathway [47]. Therefore, SIGNR1 may promote uptake of OMLs through the activated complement pathway, and this step may be essential in the development of robust cell-mediated immune responses against the antigens in OMLs [35].

\section{Phagocytic Cells Are Stimulated in Response to In Vivo Uptake of OMLs}

To achieve effective antigen delivery to the APCs for vaccination, the vector must have the capacity to deliver stimulatory signals to APCs [6]. To determine whether OMLs could deliver stimulatory signals to APCs, we evaluated the adjuvant activity of OMLs based on the expression of costimulatory molecules and MHC class II molecules on peritoneal phagocytic cells. Following in vivo uptake of OMLs, expression of CD40, CD80, CD86, and MHC class II molecules on the OML-containing cells was clearly enhanced without any additional adjuvants or encased antigens [48]. We also demonstrated that expression of CCR7 was clearly upregulated on the cells with ingested OMLs [49]. Expression of CCR7 is essential for trafficking of APCs to secondary lymphoid organs and presentation of antigens to naïve $\mathrm{T}$ cells [50]. Indeed, we found that peritoneal phagocytic cells migrated to the spleen from the peritoneal cavity within $18 \mathrm{~h}$ after OML uptake. In addition, a fraction of peritoneal phagocytic cells can differentiate into mature APCs with a DC-like phenotype [51]. Therefore, OML uptake can induce activation, differentiation, and maturation of APCs, and thus OML itself exhibits potency as an adjuvant.

We have also demonstrated that peritoneal phagocytic cells preferentially produce IL-12 in response to OML uptake (Figure 3) [45]. Further analyses have revealed that peritoneal phagocytic cells with a DC-like phenotype, which express CD11c, CD86, and MHC class II, are responsible for the production of IL-12 [49]. These findings provide important evidence supporting the activation of APCs by OMLs. Since IL-12 is critical for the development of Thl cells and the initiation of cell-mediated immune responses [50], the production and secretion of IL-12 from OML-containing DClike cells may be crucial in the induction of OML-stimulated Th1 immune responses. Interestingly, the production of IL12 from peritoneal cells was clearly augmented, while the production of IL- $1 \beta$ and IL- 6 from these cells was suppressed following incorporation of OML (Figure 3). It is generally accepted that TLRs play a key role in pathogen recognition and activation of APCs. The binding of PAMPs to TLRs triggers signal transduction events that lead to the activation of mitogen-activated protein kinases and transcription factors, such as NF- $\kappa \mathrm{B}$, resulting in proinflammatory responses, including the production of proinflammatory cytokines, such as TNF- $\alpha$, IL-12, IL-6, and IL-1 $\beta$ [27]. Indeed, TLR ligands, such as CpG-ODN or LPS, induce the production of IL- 12 and high levels of IL- $1 \beta$ and IL- 6 from peritoneal phagocytic cells [45]. In addition, peritoneal phagocytic cells from TLR4-dysfunctional $\mathrm{C} 3 \mathrm{H} / \mathrm{HeJ}$ mice also produced 

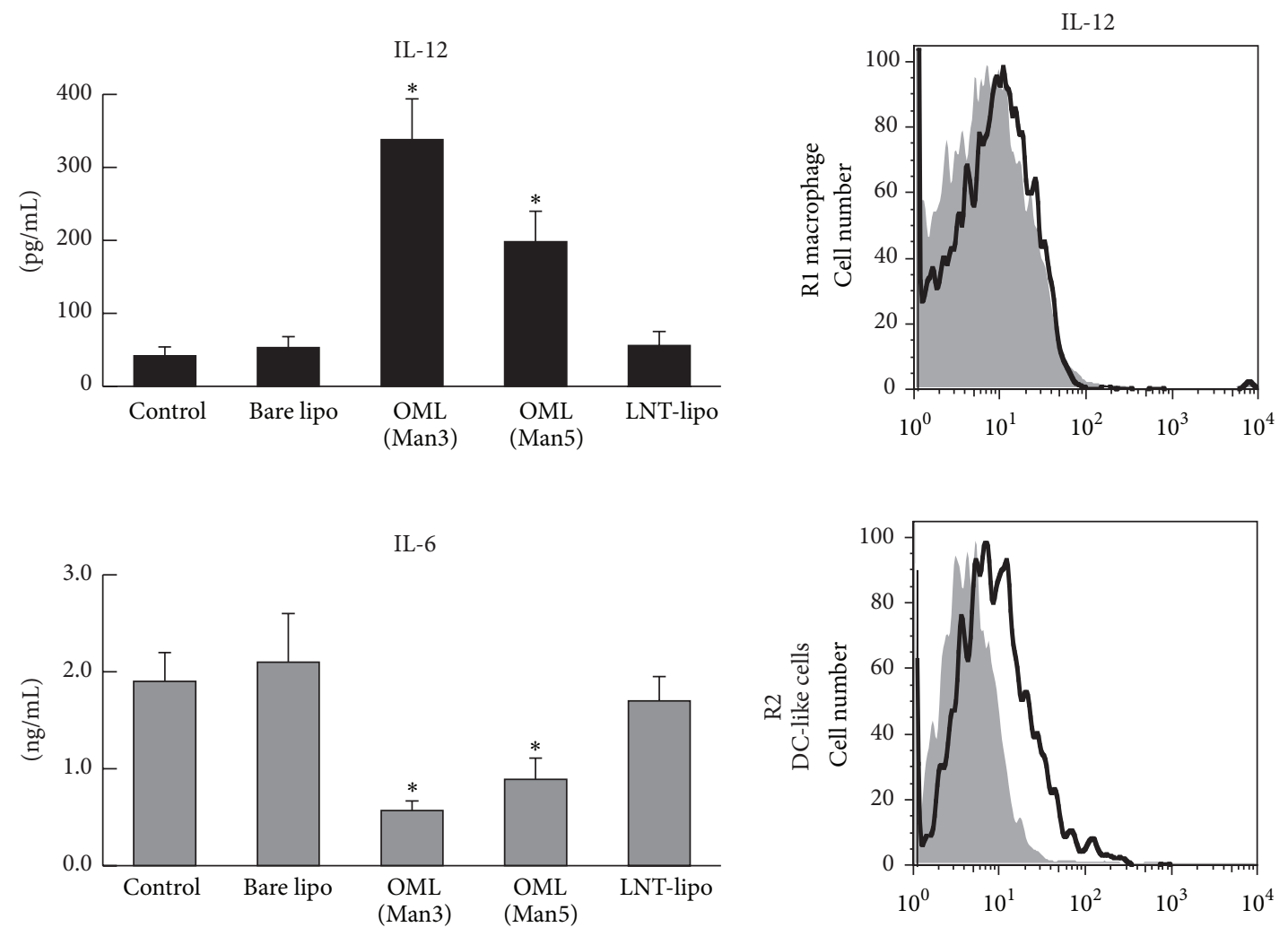

(a)

(b)

FIGURE 3: Preferential secretion of IL-12 from phagocytic cells. (a) The peritoneal phagocytic cells were collected $1 \mathrm{~h}$ after the administration of liposomes into peritoneal cavity and cultured for $18 \mathrm{~h}$. IL-12 and IL-6 secreted into culture media were determined. Note that specific IL-12 production and suppression of IL-6 production were observed in the cells that took up OMLs (Man3 or Man5), while carbohydrate uncoated liposomes (Bare lipo) and liposomes coated with lacto-N-tetraose, which has terminal galactose residue (LNT), were not affected in secretion of IL-12 and IL-6. (b) Intracellular staining of IL-12 of peritoneal phagocytic cells that ingested OMLs. IL-12 was produced by CD11b ${ }^{+}$CD11c ${ }^{+}$ (R2 in Figure 2) cells.

IL-12 upon uptake of OMLs. Therefore, OMLs might activate APCs through particular signaling pathways that are distinct from those triggered by TLRs, leading to specific production of IL-12 and to suppression of IL- 6 and IL-1 $\beta$ production. Although the detailed signaling pathways triggered by OMLs remain to be elucidated, novel adjuvant activities of OMLs might enhance immunogenicity of antigens and promote DC maturation, leading to encased-antigen-specific immune responses.

\section{OMLs Deliver the Encased Antigen to MHCs to Induce Antigen-Specific Th1 Immune Responses and the Production of Cytotoxic T Cells}

In order to reject invading pathogens and cancer cells, the concomitant activation of both $\mathrm{CD}^{+}$and $\mathrm{CD} 4^{+} \mathrm{T}$ cells and the selective activation of $\mathrm{CD} 4^{+} \mathrm{T}$ cells with helper function are required [52]. In general, exogenous antigens presented by MHC class II molecules are intended for $\mathrm{CD} 4^{+} \mathrm{T}$ cells, while internal antigens from components of virus-infected cells and cancer antigens are presented on MHC class I molecules for the activation of $\mathrm{CD}^{+} \mathrm{T}$ cells. Therefore, the vehicles must deliver the administered exogenous antigens to both MHC class I and class II pathways. We demonstrated the usefulness of OMLs as carriers for the delivery of encased antigens to both the MHC class I and class II pathways. This ability was evaluated using ovalbumin- (OVA-) specific T cell receptor transgenic OT-I (specific for $\mathrm{H}-2 \mathrm{~Kb} / \mathrm{OVA}_{257-264}$ ) and OT-II (specific for $\mathrm{H} 2 \mathrm{Ab} / \mathrm{OVA}_{323-339}$ ) mice, respectively. The peritoneal phagocytic cells that were treated with OMLs containing entrapped OVA (OML/OVA) led to significant increases in IFN- $\gamma$ production from $\mathrm{CD}^{+} \mathrm{T}$ cells from OT-I mice or $\mathrm{CD}^{+} \mathrm{T}$ cells from OT-II mice compared with cells that were treated with OVA alone, strongly indicating that the OML/OVA-ingesting phagocytic cells effectively activated OVA-specific $\mathrm{CD}^{+}$and $\mathrm{CD} 4^{+} \mathrm{T}$ cells via presentation of OVA peptides on MHC class I and class II molecules, respectively [53].

We also demonstrated that OMLs could generate encased-antigen-specific CTLs [24]. C57BL/6 mice were immunized biweekly three times with OML containing $1 \mu \mathrm{g}$ OVA, and then spleen cells were isolated from the mice one week after the last immunization. $\mathrm{CD}^{+}$cells were prepared from spleen cells after in vitro stimulation of spleen cells with 
OVA, cocultured with target cells (E.G7-OVA or EL4), and the cytotoxicity was measured. Only $\mathrm{CD}^{+}$cells from mice immunized with OML/OVA, and not those from mice treated with OVA-containing naked liposomes, exhibited strong cytotoxicity against E.G7-OVA (OVA-transfected EL4), but not against parental EL4 tumor cells. In addition, only mice immunized with OML/OVA rejected E.G7-OVA, but not parenteral EL4. On the other hand, when the EL4 tumor cell lysate was used for tumor antigens, all mice that received EL4 tumor cell lysate-containing OML completely rejected the EL4 tumor, whereas EL4 tumor growth was seen in the mice which received EL4 tumor cell lysate-containing naked liposomes. Identification of tumor-associated antigens (TAAs) that elicit tumor-specific CTL responses facilitates the development of cancer immunotherapy. Several groups have attempted to develop a vaccine strategy using tumor cell lysates as a possible TAA source, since TAAs have yet to be identified for most human cancers. Therefore, our OMLbased approach may be promising in TAA-based cancer immunotherapy.

In contrast, the induction of antigen-specific Th1 immune responses was demonstrated using an infection model of mice with Leishmania major [22, 54]. The Th1 immune response is the key event in preventing $L$. major infection, and in a resistant mouse strain the infection predominantly induces the onset of a Th1 immune response that leads to recovery from infection. Susceptible mouse strains, such as BALB/c, preferentially develop a Th2 immune response characterized by enhanced expression of IL-4, and exhibit nonhealing lesions and disease progression $[55,56]$. Intraperitoneal immunization of $\mathrm{BALB} / \mathrm{c}$ mice with OMLs with encased soluble leishmanial antigen enhanced antigenspecific IFN- $\gamma$ production, suppressed IL-4 production from spleen cells, and protected against subsequent L. major infection, indicating that Th1 immune responses predominated over Th2 immune responses in the OML-treated BALB/c mice. Administration of antigen alone or antigen-encased naked liposomes failed to induce similar immune responses. Collectively, these results indicate that OMLs can be used as an effective antigen delivery vehicle and as an APC activation system for immunotherapy with activation of both Thl cells and CTLs.

\section{OMLs Deliver the Lipid Antigen to CD1d to Activate NKT Cells}

A subpopulation of $\mathrm{T}$ cells, referred to as invariant natural killer $\mathrm{T}$ (iNKT) cells, can recognize glycolipid antigens presented by the MHC class 1-like molecule, CD1d [57, 58]. The glycolipid antigen, alpha-galactosylceramide ( $\alpha \mathrm{GC})$, has been used as an exogenous ligand for CD1d to stimulate mouse V $\alpha 14$ NKT and human V $\alpha 24$ NKT cells [59]. The antitumor and anti-infectious properties of $\alpha \mathrm{GC}$ have also attracted attention, since $\alpha \mathrm{GC}$-reactive iNKT cells rapidly produce significant amounts of Th1 and Th2 cytokines in response to stimulation, which can subsequently activate other immune cells, such as natural killer (NK) cells. By analogy, with the effective delivery of liposome-encased protein antigens to MHC class I and class II molecules, we hypothesized that OMLs could also be used as a vehicle for preferential delivery of lipid antigens, such as $\alpha \mathrm{GC}$, to CD1d to activate iNKT cells.

To this end, we prepared $\alpha \mathrm{GC}$-containing liposomes coated with Man3-DPPE ( $\alpha$ GC-OMLs) and with no coating ( $\alpha$ GC-BLs), which consisted of cholesterol, DPPC, Man3DPPE, and $\alpha \mathrm{GC}$ at molar ratios of $10: 10: 1: 1$ and $10: 10: 0: 1$, respectively, and compared the in vitro and in vivo responses of iNKT cells to $\alpha$ GC-OMLs and to $\alpha$ GC-BLs. GC-OMLs stimulated iNKT cells to produce IFN- $\gamma$ more efficiently than $\alpha \mathrm{GC}$-BLs or soluble $\alpha \mathrm{GC}$ in vitro [60]. This property of $\alpha \mathrm{GC}$-OMLs appeared to be due to preferential uptake by phagocytic cells, relative to $\alpha \mathrm{GC}$-BLs or soluble $\alpha \mathrm{GC}$. Indeed, we showed that $\alpha \mathrm{GC}$-OMLs were preferentially incorporated into splenic DCs as well as BMDCs in vitro, compared with $\alpha \mathrm{GC}$-BLs. Systemic administration of $\alpha \mathrm{GC}$ OMLs led to more rapid and continuous IFN- $\gamma$ release in sera, compared to $\alpha \mathrm{GC}$-BLs or soluble $\alpha \mathrm{GC}$, and also resulted in a more dramatic expansion of iNKT cells in peripheral blood, compared with $\alpha$ GC-BLs or soluble $\alpha \mathrm{GC}$ [60]. Since in vivo activation of iNKT cells with $\alpha \mathrm{GC}$ stimulation is known to be characterized by rapid expansion [61], $\alpha \mathrm{GC}$ OMLs activate iNKT cells in vivo with much higher efficacy than $\alpha \mathrm{GC}$-BLs or soluble $\alpha \mathrm{GC}$ via effective delivery of $\alpha \mathrm{GC}$ to CD1d. Collectively, our current results indicate that $\alpha \mathrm{GC}$-formulated particles modified by carbohydrate ligands of DC-restricted CLRs can be used as more appropriate in vivo and ex vivo delivery systems of lipid antigens to APCs to activate iNKT cells, compared with particles lacking carbohydrates.

\section{Therapeutic Application of OML-Based Vaccines}

The increasing knowledge of the effects of OMLs on APCs led us to test an OML-based vaccine for control of diseases in which antigen-specific Th1 cells and/or CTLs are the main effectors. The therapeutic efficacies of the OML-based vaccines tested to date are summarized in Table 1. One promising finding was initially obtained in a murine model of L. major infection, as described above $[22,54]$. Preliminary studies of the effects of OML-based vaccines administered via the subcutaneous route have also been performed using soluble protozoan lysates of Toxoplasma gondii, Trypanosoma brucei gambiense, and Babesia rodhaini in the corresponding protozoan infections in mice, and these studies indicated that the OML-based vaccine is effective against protozoan infection in mice. We also showed that OMLs could also control the infection of Neospora caninum in mice using recombinant antigens. Subcutaneous administration of OMLs with encased recombinant Neospora antigen NcGRA7 was able to prevent transition of infection to the brain and transplacental vertical transmission [23]. In addition, immunization with OMLs and encased apical membrane antigen 1 of Neospora reduced offspring mortality [62]. Based on these protective effects of OML-based vaccines against protozoan infections 
TABLE 1: Therapeutic application of OML-based vaccine in murine, bovine, and human models.

\begin{tabular}{|c|c|c|c|c|}
\hline Encased materials & Responses & Animal or source & Route & References \\
\hline OVA & Elimination of established E.G7-OVA tumor & C57/BL6 & s.c. & {$[24,53]$} \\
\hline $\begin{array}{l}\text { Crude extract of } \\
\text { Leishmania }\end{array}$ & $\begin{array}{l}\text { Suppression of footpad swelling by Leishmania major } \\
\text { infection }\end{array}$ & $\mathrm{Balb} / \mathrm{c}$ & i.p. & {$[22]$} \\
\hline Recombinant NcGRA7 & $\begin{array}{l}\text { Protection of dams and offspring from Neospora } \\
\text { caninum infection }\end{array}$ & $\mathrm{Balb} / \mathrm{c}$ & s.c. & {$[23]$} \\
\hline $\begin{array}{l}\text { Recombinant apical } \\
\text { membrane antigen } 1\end{array}$ & $\begin{array}{l}\text { Reduction of offspring mortality from Neospora } \\
\text { caninum infection }\end{array}$ & $\mathrm{Balb} / \mathrm{c}$ & s.c. & {$[62]$} \\
\hline Cry j 1 & $\begin{array}{l}\text { Prevention of IgE elevation in sera in response to } \\
\text { Cry j } 1 \text { sensitization }\end{array}$ & $\mathrm{Balb} / \mathrm{c}$ & s.c. & {$[25]$} \\
\hline OVA & $\begin{array}{l}\text { Induce mucosal immune responses and suppression } \\
\text { of development of allergic diarrhea induced by oral } \\
\text { OVA administration }\end{array}$ & $\mathrm{Balb} / \mathrm{c}$ & i.n. & {$[67,68]$} \\
\hline$\alpha$ GalCer & More effective expansion of NKT cells & C57/BL6 & i.p. & {$[60]$} \\
\hline Recombinant NcGRA7 & $\begin{array}{l}\text { Suppression of serum IFN- } \gamma \text { elevation by infection of } \\
\text { Neospora, suppression of Neospora infection in brain }\end{array}$ & Cattle & s.c. & {$[63]$} \\
\hline \multirow{2}{*}{$\begin{array}{l}\text { HLA-restricted HTLV-1 } \\
\text { Tax epitope peptide }\end{array}$} & Induction of HTLV-1-specific CTL & HLA-transgenic mouse & s.c. & \multirow{2}{*}[70]{} \\
\hline & Induction of HTLV-1-specific CTL & PBMC from HTLV-1 carriers & In vitro & \\
\hline \multirow{2}{*}{$\begin{array}{l}\text { HLA-A24-restricted } \\
\text { surviving } 2 \text { B epitope } \\
\text { peptide }\end{array}$} & $\begin{array}{l}\text { Induction of CTL specific for HLA-restricted } \\
\text { surviving 2B epitope }\end{array}$ & PBMC from patients & In vitro & \multirow{2}{*}{ a } \\
\hline & $\begin{array}{l}\text { Elimination of established surviving 2B-positive } \\
\text { tumor }\end{array}$ & HLA-transgenic mouse & s.c. & \\
\hline $\begin{array}{l}\text { Human papillomavirus } \\
\text { DNA }\end{array}$ & Induction of papillomavirus-specific CTL & PBMC from carriers & In vitro & {$[71]$} \\
\hline
\end{tabular}

i.n.: intranasal.

${ }^{a}$ Personal communication.

in murine models, we assessed the effects of OML-based vaccine in farm animals. Subcutaneous administration of OMLs with encased recombinant NcGRA7 can induce protective immune responses to $N$. caninum in cattle [63], indicating that OML-based vaccines may be useful for prophylaxis against some infectious diseases in animal husbandry.

Type I allergic reactions depend on allergen-specific Th2 cells, which produce IL-4 and IL-5 and promote synthesis of IgE [64]. IFN- $\gamma$ produced by Th1 cells inhibits the development and activation of Th 2 cells and prevents IgE production $[65,66]$ and OMLs can induce encased-antigen-specific Th1 immune responses. Consequently, OML-based vaccines with encased allergens are expected to exhibit antiallergic effects. One promising antiallergic effect of an OML-based vaccine has been demonstrated in an animal model for Japanese cedar pollinosis [25]. Immunization of OMLs with entrapped Cry j 1, which has been identified as a major allergen in Japanese cedar pollen, has been shown to inhibit the elevation of the serum IgE level elicited by Cry j 1 administration in both nonsensitized mice and Cry j 1-presensitized mice. This inhibitory effect might occur through a shift from a Th2 immune response to an allergen-specific Th1 immune response, since Cry j 1-specific IgG1, which is mediated by Th2 cells, was significantly reduced, whereas Cry j 1specific IgG2a, which is produced by Th1 cells, was increased in sera from OML-based vaccinated mice. Recently, it was demonstrated that intranasal administration of OML-based vaccines could induce both mucosal and systemic immune responses and suppress the development of allergic diarrhea induced by oral OVA administration $[67,68]$. Therefore, OML-encased allergens may serve as immunotherapeutic agents to control allergic diseases including food allergies.

Since tumor-specific CTLs are the most important effector cells for antitumor immunity, an OML-based vaccine with an encased tumor antigen might be useful in antitumor therapy. Induction of antitumor immunity in an animal bearing a large tumor mass is difficult, since an immunosuppressive environment develops along with tumor growth [69]. Thus, we evaluated OML-based vaccination to assess its clinical utility in the eradication of an established tumor [24]. OMLbased vaccination elicited sufficient antitumor immunity to suppress tumor growth and led to tumor rejection: a single injection of OMLs containing $1 \mu \mathrm{g}$ of antigen induced antitumor activity in model E.G7-OVA tumor-bearing mice, and about half of the mice exhibited elimination of an established E.G7-OVA tumor (Figure 4). A similar suppressive effect was not observed in mice that received empty OMLs or a mixture of soluble OVA and empty OMLs, suggesting that effective antigen delivery by antigen-carrying OMLs is important in induction of systemic immune responses.

In the majority of studies including ours, murine models were used to assess the clinical utility of the antigen delivery systems. However, assessment using human systems is essential in the consideration of clinical application. Recently, several groups have demonstrated that OMLs could generate encased-antigen-specific immune responses not only 


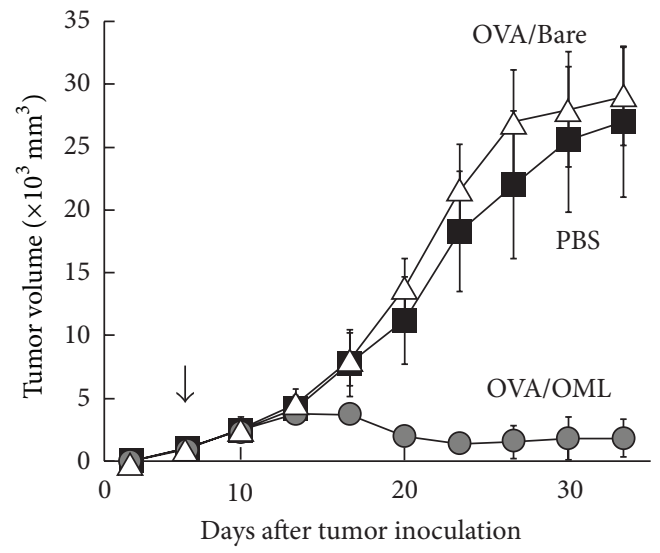

(a)

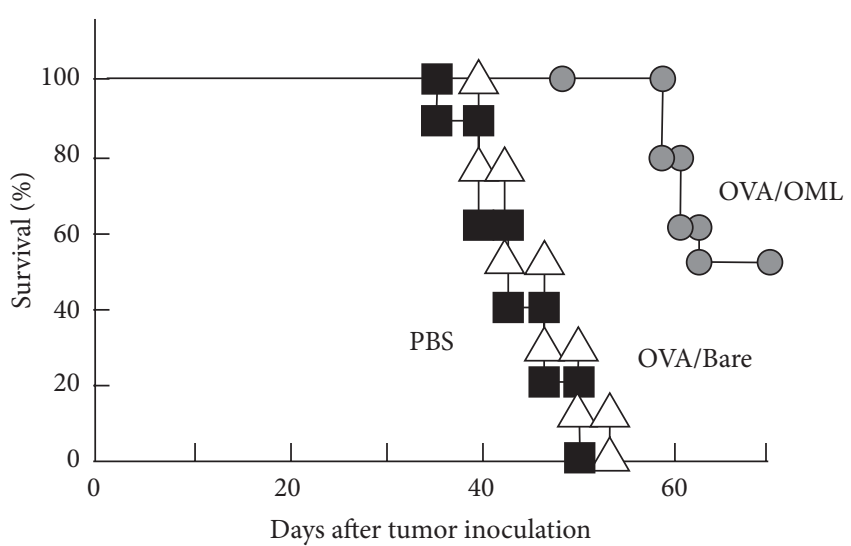

(b)

FIGURE 4: Elimination of established tumor by administration of OML-based vaccine. Mice $(n=25)$ were challenged by s.c. injection of E.G7OVA tumor cells in the right dorsal area on day 0. On day 9, OML/OVA, Bare/OVA, or PBS was injected into the side where the tumor had grown. (a) Suppression of tumor growth. (b) Surviving mice, expressed as a percentage of the total number of mice in each group.

in murine system but also in human systems. Kazako and colleagues demonstrated that OMLs with a specific antigen peptide of human T cell leukemia virus-1 (HTLV-1) encased could induce HTLV-1-specific CTLs in HLA-transgenic mice and in PBMCs from HTLV-1 carriers [70]. In addition, antigenic peptide-containing OMLs can induce CTLs specific to the HLA-restricted epitopes of survivin $2 \mathrm{~B}$, which is expressed in many types of tumors, in PBMCs obtained from patients in vitro and in HLA-transgenic mice in vivo (personal communication). OMLs could not only deliver the protein antigens but also DNAs encoding specific antigens to APCs to induce specific immune response. Mizuuchi et al. generated a human papilloma virus gene-containing OMLs (OML-HPV) and showed that HPV-specific CTLs could be generated from PBMC of HPV-positive cervical carcinoma patients by stimulating OML-HPV [71]. These feasibility studies of OMLbased vaccines using murine, bovine, and human models, as shown in Table 1, have revealed their potential for clinical use in vaccination for various diseases in which CTLs and/or Th1 cells act as effector cells.

\section{Conclusion and Future Perspectives}

Strategies that target APCs and modulate function of APCs in vivo can have significant implications for vaccine design. A large number of particulate carriers are now available for antigen delivery to APCs and uptake of particulate carriers with or without surface-conjugated targeting ligands by APCs has been demonstrated in in vitro and in vivo animal studies $[4,72,73]$. The recent emergence of carriers to deliver antigens and drugs to cells by carbohydrate ligands for lectin receptors has also demonstrated the exciting potential for developing new therapeutic technology $[74,75]$. For example, liposomes decorated with carbohydrate ligands for CD169 have recently been shown to be suitable for the targeted delivery of protein and lipid antigens to macrophages via CD169-mediated endocytosis [76, 77]. However, many of these carriers could not deliver the stimulatory signals to
APCs and therefore require concomitant administration of additional adjuvants to activate APCs.

In comparison to other carriers for antigen delivery to APCs, OMLs have an excellent ability in achieving concomitant delivery of antigen and stimulatory signals to professional phagocytic cells, such as DCs and macrophages, leading to APC maturation, presentation of antigens on MHC class I and class II molecules, secretion of IL-12 from APCs, and migration of APCs into lymphoid tissues from peripheral tissues, where both naive $\mathrm{CD}^{+}$and $\mathrm{CD}^{+} \mathrm{T}$ cells are activated to generate encased-antigen-specific Th1 cells and CTLs, respectively. Therefore, OMLs themselves have the potential for clinical use in vaccination against diseases in which CTLs and/or Thl cells act as effector cells.

Similar to the studies of other delivery systems, the focus of the studies of OMLs was on demonstrating immune activation without focusing on the underlying mechanisms that lead to activation of APCs. For example, the molecular mechanism and signaling that IL-12 production is preferentially enhanced and IL-6 production is suppressed in OMLingesting phagocytic cells are still unclear, although this characteristic property of OMLs might be essential for the specific induction of encased-antigen-specific cellular immune responses. An increased focus on mechanistic studies of activation of APCs with liposome-based antigen delivery systems is required for successful development. The critical factors of the liposomes for uptake and activation of APCs, for example, carbohydrate density and particle size, remain to be elucidated. We usually use OMLs consisting of DPPC, cholesterol, and Man3-DPPE at a molar ratio of $10: 10: 1$ and with a $1 \mu \mathrm{m}$ particle size, which have the capacity to induce strong cellular immune responses and control several diseases, since nanoparticles of 500-2000 nm size were found to be more efficiently uptaken as compared to smaller size. A preliminary study suggested that OMLs with a lower carbohydrate density or a smaller particle size did not induce cellular immune responses as well as IL-12 production. Thus, optimization of the carbohydrate density on the liposome 
surface and of the particle size is also necessary. However, as the understanding of signaling in APCs and formulation factors that determine immune response will progress in the future, it is without doubt that clinical application of APC-targeted carbohydrate-coated liposomal delivery and activation systems will become a reality.

\section{Acknowledgments}

The authors would like to thank Dr. Yoshifumi Nishikawa, Dr. Yuzuru Ikehara, and Dr. Naoyuki Yokoyama for helpful discussions.

\section{References}

[1] K. Palucka and J. Banchereau, "Dendritic cells: a link between innate and adaptive immunity," Journal of Clinical Immunology, vol. 19, no. 1, pp. 12-25, 1999.

[2] B. Pulendran, J. L. Smith, G. Caspary et al., "Distinct dendritic cell subsets differentially regulate the class of immune response in vivo," Proceedings of the National Academy of Sciences of the United States of America, vol. 96, no. 3, pp. 1036-1041, 1999.

[3] J. Banchereau and R. M. Steinman, "Dendritic cells and the control of immunity," Nature, vol. 392, no. 6673, pp. 245-252, 1998.

[4] D. T. O'Hagan and N. M. Valiante, "Recent advances in the discovery and delivery of vaccine adjuvants," Nature Reviews Drug Discovery, vol. 2, no. 9, pp. 727-735, 2003.

[5] P. J. Tacken, R. Torensma, and C. G. Figdor, "Targeting antigens to dendritic cells in vivo," Immunobiology, vol. 211, no. 6-8, pp. 599-608, 2006.

[6] G. Morón, G. Dadaglio, and C. Leclerc, "New tools for antigen delivery to the MHC class I pathway," Trends in Immunology, vol. 25, no. 2, pp. 92-97, 2004.

[7] I. A. F. M. Heijnen, M. J. Van Vugt, N. A. Fanger et al., "Antigen targeting to myeloid-specific human $\mathrm{Fc} \gamma \mathrm{RI} / \mathrm{CD} 64$ triggers enhanced antibody responses in transgenic mice," Journal of Clinical Investigation, vol. 97, no. 2, pp. 331-338, 1996.

[8] Y. Liu, X. Gao, E. Masuda, P. B. Redecha, M. C. Blank, and L. Pricop, "Regulated expression of Fc $\gamma \mathrm{R}$ in human dendritic cells controls cross-presentation of antigen-antibody complexes," Journal of Immunology, vol. 177, no. 12, pp. 8440-8447, 2006.

[9] I. Mende, P. Hoffmann, A. Wolf et al., "Highly efficient antigen targeting to M-DC8+ dendritic cells via Fc $\gamma$ RIII/CD16-specific antibody conjugates," International Immunology, vol. 17, no. 5, pp. 539-547, 2005.

[10] P. Guermonprez, N. Khelef, E. Blouin et al., "The adenylate cyclase toxin of Bordetella pertussis binds to target cells via the $\alpha \mathrm{M} \beta 2$ integrin (CD11b/CD18)," Journal of Experimental Medicine, vol. 193, no. 9, pp. 1035-1044, 2001.

[11] T. Storni, T. M. Kündig, G. Senti, and P. Johansen, "Immunity in response to particulate antigen-delivery systems," Advanced Drug Delivery Reviews, vol. 57, no. 3, pp. 333-355, 2005.

[12] Y. Men, H. Tamber, R. Audran, B. Gander, and G. Corradin, "Induction of a cytotoxic $\mathrm{T}$ lymphocyte response by immunization with a malaria specific CTL peptide entrapped in biodegradable polymer microspheres," Vaccine, vol. 15, no. 1213, pp. 1405-1412, 1997.

[13] N. M. Wassef, C. R. Alving, and R. L. Richards, "Liposomes as carriers for vaccines," ImmunoMethods, vol. 4, no. 3, pp. 217$222,1994$.
[14] J. G. Altin, C. L. Van Broekhoven, and C. R. Parish, "Targeting dendritic cells with antigen-containing liposomes: antitumour immunity," Expert Opinion on Biological Therapy, vol. 4, no. 11, pp. 1735-1747, 2004.

[15] C. L. Van Broekhoven, C. R. Parish, C. Demangel, W. J. Britton, and J. G. Altin, "Targeting dendritic cells with antigencontaining liposomes: a highly effective procedure for induction of antitumor immunity and for tumor immunotherapy," Cancer Research, vol. 64, no. 12, pp. 4357-4365, 2004.

[16] S. K. Sharma, A. Dube, A. Nadeem et al., "Non PC liposome entrapped promastigote antigens elicit parasite specific $\mathrm{CD} 8^{+}$ and $\mathrm{CD} 4^{+} \mathrm{T}$-cell immune response and protect hamsters against visceral leishmaniasis," Vaccine, vol. 24, no. 11, pp. 1800-1810, 2006.

[17] G. Chikh and M.-P. Schutze-Redelmeir, "Liposomal delivery of CTL epitopes to dendritic cells," Bioscience Reports, vol. 22, no. 2, pp. 339-353, 2002.

[18] T. Nakanishi, J. Kunisawa, A. Hayashi et al., "Positively charged liposome functions as an efficient immunoadjuvant in inducing cell-mediated immune response to soluble proteins," Journal of Controlled Release, vol. 61, no. 1-2, pp. 233-240, 1999.

[19] B. Guy, N. Pascal, A. Françon et al., "Design, characterization and preclinical efficacy of a cationic lipid adjuvant for influenza split vaccine," Vaccine, vol. 19, no. 13-14, pp. 1794-1805, 2001.

[20] J. W. Park, D. B. Kirpotin, K. Hong et al., "Tumor targeting using anti-her2 immunoliposomes," Journal of Controlled Release, vol. 74, no. 1-3, pp. 95-113, 2001.

[21] R. K. Gieseler, G. Marquitan, M. J. Hahn et al., "DC-SIGNspecific liposomal targeting and selective intracellular compound delivery to human myeloid dendritic cells: implications for HIV disease," Scandinavian Journal of Immunology, vol. 59, no. 5, pp. 415-424, 2004.

[22] Y. Shimizu, K. Yamakami, T. Gomi et al., "Protection against Leishmania major infection by oligomannose-coated liposomes," Bioorganic and Medicinal Chemistry, vol. 11, no. 7, pp. 1191-1195, 2003.

[23] Y. Nishikawa, H. Zhang, Y. Ikehara, N. Kojima, X. Xuan, and $\mathrm{N}$. Yokoyama, "Immunization with oligomannose-coated liposome-entrapped dense granule protein 7 protects dams and offspring from Neospora caninum infection in mice," Clinical and Vaccine Immunology, vol. 16, no. 6, pp. 792-797, 2009.

[24] N. Kojima, L. Biao, T. Nakayama, M. Ishii, Y. Ikehara, and K. Tsujimura, "Oligomannose-coated liposomes as a therapeutic antigen-delivery and an adjuvant vehicle for induction of in vivo tumor immunity," Journal of Controlled Release, vol. 129, no. 1, pp. 26-32, 2008 .

[25] M. Ishii, A. Koyama, H. Iseki, H. Narumi, N. Yokoyama, and N. Kojima, "Anti-allergic potential of oligomannose-coated liposome-entrapped Cry j 1 as immunotherapy for Japanese cedar pollinosis in mice," International Immunopharmacology, vol. 10, no. 9, pp. 1041-1046, 2010.

[26] C. A. Janeway Jr. and R. Medzhitov, "Innate immune recognition," Annual Review of Immunology, vol. 20, pp. 197-216, 2002.

[27] T. Kawai and S. Akira, "Pathogen recognition with Toll-like receptors," Current Opinion in Immunology, vol. 17, no. 4, pp. 338-344, 2005.

[28] E. P. McGreal, L. Martinez-Pomares, and S. Gordon, "Divergent roles for C-type lectins expressed by cells of the innate immune system," Molecular Immunology, vol. 41, no. 11, pp. 1109-1121, 2004.

[29] T. B. H. Geijtenbeek, S. J. Van Vliet, A. Engering, B. A. 'T Hart, and Y. Van Kooyk, "Self- and nonself-recognition by C-type 
lectins on dendritic cells," Annual Review of Immunology, vol. 22, pp. 33-54, 2004.

[30] M. J. Robinson, D. Sancho, E. C. Slack, S. LeibundGutLandmann, and C. R. Sousa, "Myeloid C-type lectins in innate immunity," Nature Immunology, vol. 7, no. 12, pp. 1258-1265, 2006.

[31] Y. van Kooyk, "C-type lectins on dendritic cells: key modulators for the induction of immune responses," Biochemical Society Transactions, vol. 36, no. 6, pp. 1478-1481, 2008.

[32] K. Mahnke, M. Guo, S. Lee et al., "The dendritic cell receptor for endocytosis, DEC-205, can recycle and enhance antigen presentation via major histocompatibility complex class IIpositive lysosomal compartments," Journal of Cell Biology, vol. 151, no. 3, pp. 673-683, 2000.

[33] A. Engering, T. B. H. Geijtenbeek, S. J. Van Vliet et al., "The dendritic cell-specific adhesion receptor DC-SIGN internalizes antigen for presentation to T cells," Journal of Immunology, vol. 168, no. 5, pp. 2118-2126, 2002.

[34] L. Bonifaz, D. Bonnyay, K. Mahnke, M. Rivera, M. C. Nussenzweig, and R. M. Steinman, "Efficient targeting of protein antigen to the dendritic cell receptor DEC-205 in the steady state leads to antigen presentation on major histocompatibility complex class I products and peripheral $\mathrm{CD} 8^{+} \mathrm{T}$ cell tolerance," Journal of Experimental Medicine, vol. 196, no. 12, pp. 1627-1638, 2002.

[35] M. W. Turner, "Mannose-binding lectin: the pluripotent molecule of the innate immune system," Immunology Today, vol. 17, no. 11, pp. 532-540, 1996.

[36] T. B. H. Geijtenbeek, R. Torensma, S. J. Van Vliet et al., "Identification of DC-SIGN, a novel dendritic cell-specific ICAM-3 receptor that supports primary immune responses," Cell, vol. 100, no. 5, pp. 575-585, 2000.

[37] C. G. Park, K. Takahara, E. Umemoto et al., "Five mouse homologues of the human dendritic cell C-type lectin, DCSIGN," International Immunology, vol. 13, no. 10, pp. 1283-1290, 2001.

[38] N. S. Stambach and M. E. Taylor, "Characterization of carbohydrate recognition by langerin, a C-type lectin of Langerhans cell," Glycobiology, vol. 13, no. 5, pp. 401-410, 2003.

[39] E. P. McGreal, M. Rosas, G. D. Brown et al., "The carbohydraterecognition domain of Dectin-2 is a C-type lectin with specificity for high mannose," Glycobiology, vol. 16, no. 5, pp. 422430, 2006.

[40] S. K. Singh, J. Stephani, M. Schaefer et al., "Targeting glycan modified OVA to murine DC-SIGN transgenic dendritic cells enhances MHC class I and II presentation," Molecular Immunology, vol. 47, no. 2-3, pp. 164-174, 2009.

[41] S. Espuelas, P. Haller, F. Schuber, and B. Frisch, "Synthesis of an amphiphilic tetraantennary mannosyl conjugate and incorporation into liposome carriers," Bioorganic and Medicinal Chemistry Letters, vol. 13, no. 15, pp. 2557-2560, 2003.

[42] S. Espuelas, C. Thumann, B. Heurtault, F. Schuber, and B. Frisch, "Influence of ligand valency on the targeting of immature human dendritic cells by mannosylated liposomes," Bioconjugate Chemistry, vol. 19, no. 12, pp. 2385-2393, 2008.

[43] K. L. White, T. Rades, S. Hook, R. H. Furneaux, and P. C. Tyler, "Mannosylated liposomes as antigen delivery vehicles for targeting to dendritic cells," Journal of Pharmacy and Pharmacology, vol. 58, no. 6, pp. 729-737, 2006.

[44] Y. Ikehara, T. Niwa, L. Biao et al., "A carbohydrate recognitionbased drug delivery and controlled release system using intraperitoneal macrophages as a cellular vehicle," Cancer Research, vol. 66, no. 17, pp. 8740-8748, 2006.

[45] H. Takagi, M. Numazaki, T. Kajiwara et al., "Cooperation of specific ICAM-3 grabbing nonintegrin-related 1 (SIGNR1) and complement receptor type 3 (CR3) in the uptake of oligomannose-coated liposomes by macrophages," Glycobiology, vol. 19, no. 3, pp. 258-266, 2009.

[46] Y. Abe, Y. Kuroda, N. Kuboki, M. Matsushita, N. Yokoyama, and N. Kojima, "Contribution of complement component C3 and complement receptor type 3 to carbohydrate-dependent uptake of oligomannose-coated liposomes by peritoneal macrophages," Journal of Biochemistry, vol. 144, no. 5, pp. 563-570, 2008.

[47] Y.-S. Kang, Y. Do, H.-K. Lee et al., "A dominant complement fixation pathway for pneumococcal polysaccharides initiated by SIGN-R1 interacting with Clq," Cell, vol. 125, no. 1, pp. 47-58, 2006.

[48] H. Takagi, N. Furuya, and N. Kojima, "Preferential production of IL-12 by peritoneal macrophages activated by liposomes prepared from neoglycolipids containing oligomannose residues," Cytokine, vol. 40, no. 3, pp. 241-250, 2007.

[49] M. Ishii, C. Kato, A. Hakamata, and N. Kojima, "Targeting with oligomannose-coated liposomes promotes maturation and splenic trafficking of dendritic cells in the peritoneal cavity," International Immunopharmacology, vol. 11, no. 2, pp. 164-171, 2011.

[50] A. Martín-Fontecha, S. Sebastiani, U. E. Höpken et al., "Regulation of dendritic cell migration to the draining lymph node: impact on T lymphocyte traffic and priming," Journal of Experimental Medicine, vol. 198, no. 4, pp. 615-621, 2003.

[51] N. Kojima, C. Kato, M. Igarashi, and M. Ishii, "Development of peritoneal macrophage along a dendritic cell lineage in response to uptake of oligomannose-coated liposomes," Cellular Immunology, vol. 271, no. 2, pp. 335-341, 2011.

[52] A. M. Leen, C. M. Rooney, and A. E. Foster, "Improving T cell therapy for cancer," Annual Review of Immunology, vol. 25, pp. 243-265, 2007.

[53] Y. Ikehara, N. Shiuchi, S. Kabata-Ikehara et al., "Effective induction of anti-tumor immune responses with oligomannosecoated liposome targeting to intraperitoneal phagocytic cells," Cancer Letters, vol. 260, no. 1-2, pp. 137-145, 2008.

[54] Y. Shimizu, H. Takagi, T. Nakayama et al., "Intraperitoneal immunization with oligomannose-coated liposome-entrapped soluble leishmanial antigen induces antigen-specific T-helper type immune response in BALB/c mice through uptake by peritoneal macrophages," Parasite Immunology, vol. 29, no. 5, pp. 229-239, 2007.

[55] J. Lehmann, K.-H. Enssle, I. Lehmann, A. Emmendörfer, and M.-L. Lohmann-Matthes, "The capacity to produce IFN- $\gamma$ rather than the presence of interleukin-4 determines the resistance and the degree of susceptibility to Leishmania donovani infection in mice," Journal of Interferon and Cytokine Research, vol. 20, no. 1, pp. 63-77, 2000.

[56] H. Himmelrich, P. Launois, I. Maillard et al., "In BALB/c mice, IL-4 production during the initial phase of infection with Leishmania major is necessary and sufficient to instruct Th2 cell development resulting in progressive disease," Journal of Immunology, vol. 164, no. 9, pp. 4819-4825, 2000.

[57] D. I. Godfrey, K. J. L. Hammond, L. D. Poulton, M. J. Smyth, and A. G. Baxter, "NKT cells: facts, functions and fallacies," Immunology Today, vol. 21, no. 11, pp. 573-583, 2000.

[58] M. Taniguchi, M. Harada, S. Kojo, T. Nakayama, and H. Wakao, "The regulatory role of V $\alpha 14$ NKT cells in innate and acquired 
immune response," Annual Review of Immunology, vol. 21, pp. 483-513, 2003.

[59] T. Kawano, J. Cui, Y. Koezuka et al., "CD1d-restricted and TCRmediated activation of $\mathrm{V}(\alpha) 14$ NKT cells by glycosylceramides," Science, vol. 278, no. 5343, pp. 1626-1629, 1997.

[60] M. Ishii and N. Kojima, "Effective stimulation of invariant natural killer T cells by oligomannose-coated liposomes," International Immunopharmacology, vol. 15, no. 4, pp. 685-692, 2013.

[61] N. Y. Crowe, A. P. Uldrich, K. Kyparissoudis et al., "Glycolipid antigen drives rapid expansion and sustained cytokine production by NK T cells," Journal of Immunology, vol. 171, no. 8, pp. 4020-4027, 2003.

[62] H. Zhang, Y. Nishikawa, J. Yamagishi et al., "Neospora caninum: application of apical membrane antigen 1 encapsulated in the oligomannose-coated liposomes for reduction of offspring mortality from infection in BALB/c mice," Experimental Parasitology, vol. 125, no. 2, pp. 130-136, 2010.

[63] M. Nishimura, J. Kohara, Y. Kuroda et al., "Oligomannosecoated liposome-entrapped dense granule protein 7 induces protective immune response to Neospora caninum in cattle," Vaccine, vol. 31, no. 35, pp. 3528-3535, 2013.

[64] J. Pene, F. Rousset, F. Briere et al., "IgE production by normal human lymphocytes is induced by interleukin 4 and suppressed by interferons $\gamma$ and $\alpha$ and prostaglandin E2," Proceedings of the National Academy of Sciences of the United States of America, vol. 85, no. 18, pp. 6880-6884, 1988.

[65] R. A. Seder and W. E. Paul, "Acquisition of lymphokineproducing phenotype by CD4+ T cells," Annual Review of Immunology, vol. 12, pp. 635-673, 1994.

[66] C. M. Snapper and W. E. Paul, "Interferon- $\gamma$ and B cell stimulatory factor-1 reciprocally regulate Ig isotype production," Science, vol. 236, no. 4804, pp. 944-947, 1987.

[67] M. Ishii and N. Kojima, "Mucosal adjuvant activity of oligomannose-coated liposomes for nasal immunization," Glycoconjugate Journal, vol. 27, no. 1, pp. 115-123, 2010.

[68] A. Kawakita, H. Shirasaki, M. Yasutomi et al., "Immunotherapy with oligomannose-coated liposomes ameliorates allergic symptoms in a murine food allergy model," Allergy, vol. 67, no. 3, pp. 371-379, 2012.

[69] T. J. Curiel, G. Coukos, L. Zou et al., "Specific recruitment of regulatory $\mathrm{T}$ cells in ovarian carcinoma fosters immune privilege and predicts reduced survival," Nature Medicine, vol. 10, no. 9, pp. 942-949, 2004.

[70] T. Kozako, S. Hirata, Y. Shimizu et al., "Oligomannose-coated liposomes efficiently induce human T-cell leukemia virus1-specific cytotoxic T lymphocytes without adjuvant," FEBS Journal, vol. 278, no. 8, pp. 1358-1366, 2011.

[71] M. Mizuuchi, Y. Hirohashi, T. Torigoe et al., "Novel oligomannose liposome-DNA complex DNA vaccination efficiently evokes anti-HPV E6 and E7 CTL responses," Experimental and Molecular Pathology, vol. 92, no. 1, pp. 185-190, 2012.

[72] M. Owais, A. K. Masood, J. N. Agrewala, D. Bisht, and C. M. Gupta, "Use of liposomes as an immunopotentiating delivery system: in perspective of vaccine development," Scandinavian Journal of Immunology, vol. 54, no. 1-2, pp. 125-132, 2001.

[73] M. A. Ansari, S. Zubair, A. Mahmood et al., "RD antigen based nanovaccine imparts long term protection by inducing memory response against experimental murine tuberculosis," PLOS ONE, vol. 6, no. 8, Article ID e22889, 2011.

[74] M. Hirai, H. Minematsu, N. Kondo, K. Oie, K. Igarashi, and N. Yamazaki, "Accumulation of liposome with Sialyl Lewis X to inflammation and tumor region: application to in vivo bioimaging," Biochemical and Biophysical Research Communications, vol. 353, no. 3, pp. 553-558, 2007.

[75] W. C. Chen, G. C. Completo, D. S. Sigal, P. R. Crocker, A. Saven, and J. C. Paulson, "In vivo targeting of B-cell lymphoma with glycan ligands of CD22," Blood, vol. 115, no. 23, pp. 4778-4786, 2010.

[76] W. C. Chen, N. Kawasaki, C. M. Nycholat et al., "Antigen delivery to macrophages using liposomal nanoparticles targeting sialoadhesin/CD169," PLoS ONE, vol. 7, no. 6, Article ID e39039, 2012.

[77] N. Kawasaki, J. L. Vela, C. M. Nycholat et al., “Targeted delivery of lipid antigen to macrophages via the CD169/sialoadhesin endocytic pathway induces robust invariant natural killer T cell activation," Proceedings of the National Academy of Sciences, vol. 110, no. 19, pp. 7826-7831, 2013. 


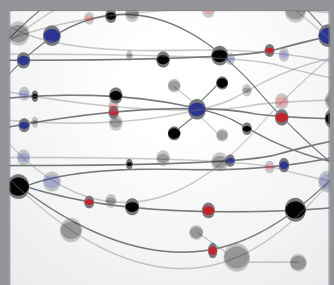

The Scientific World Journal
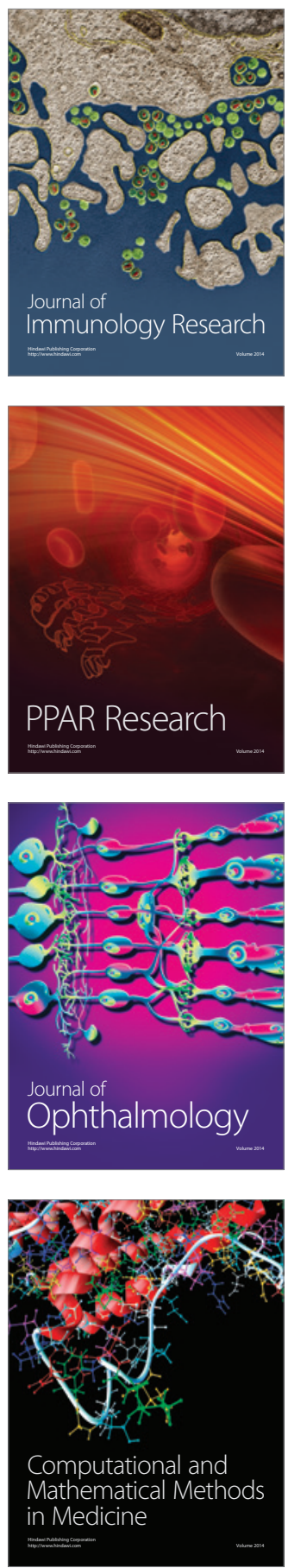

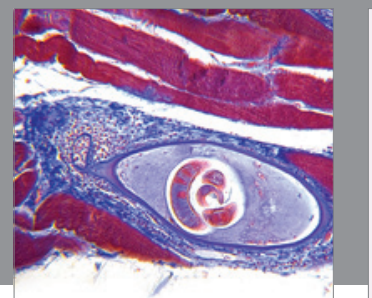

Gastroenterology

Research and Practice
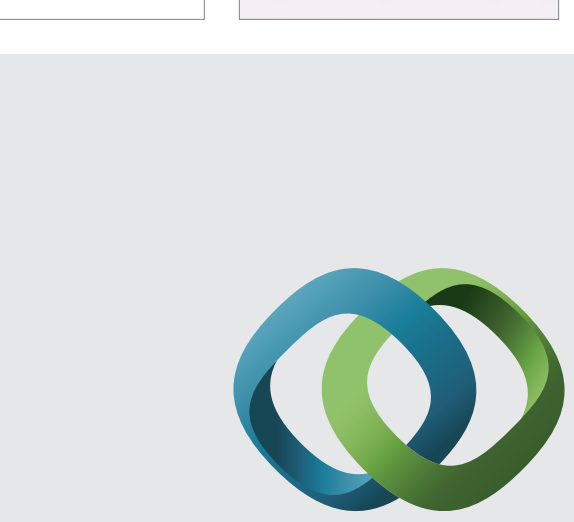

\section{Hindawi}

Submit your manuscripts at

http://www.hindawi.com
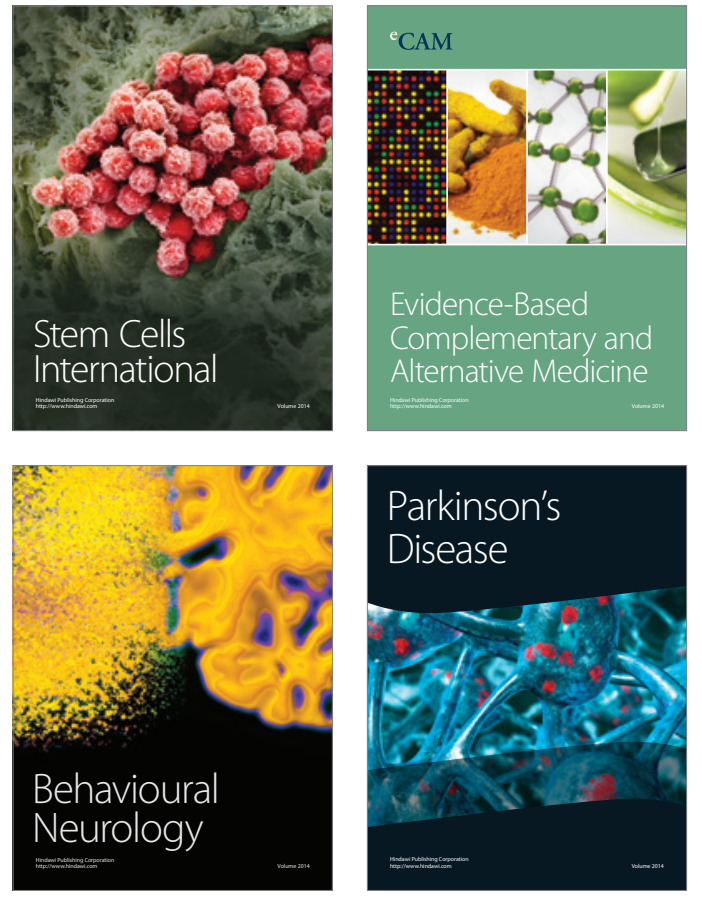
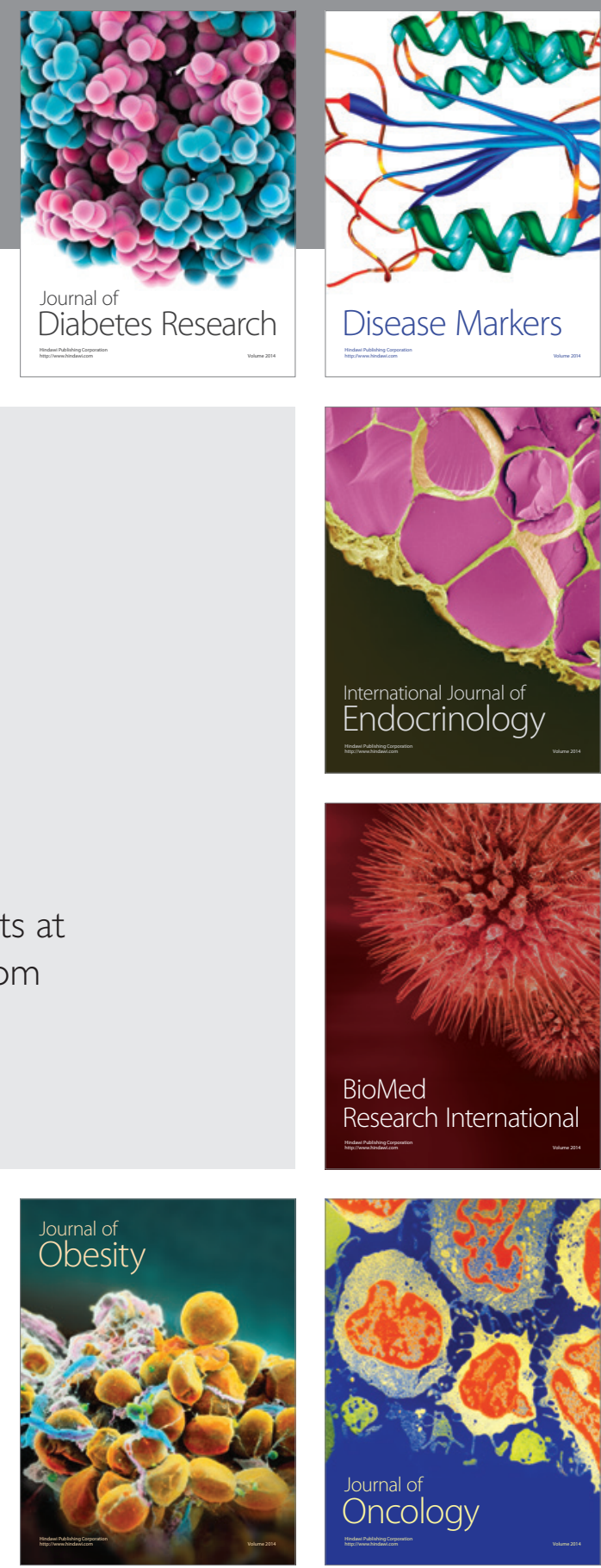

Disease Markers
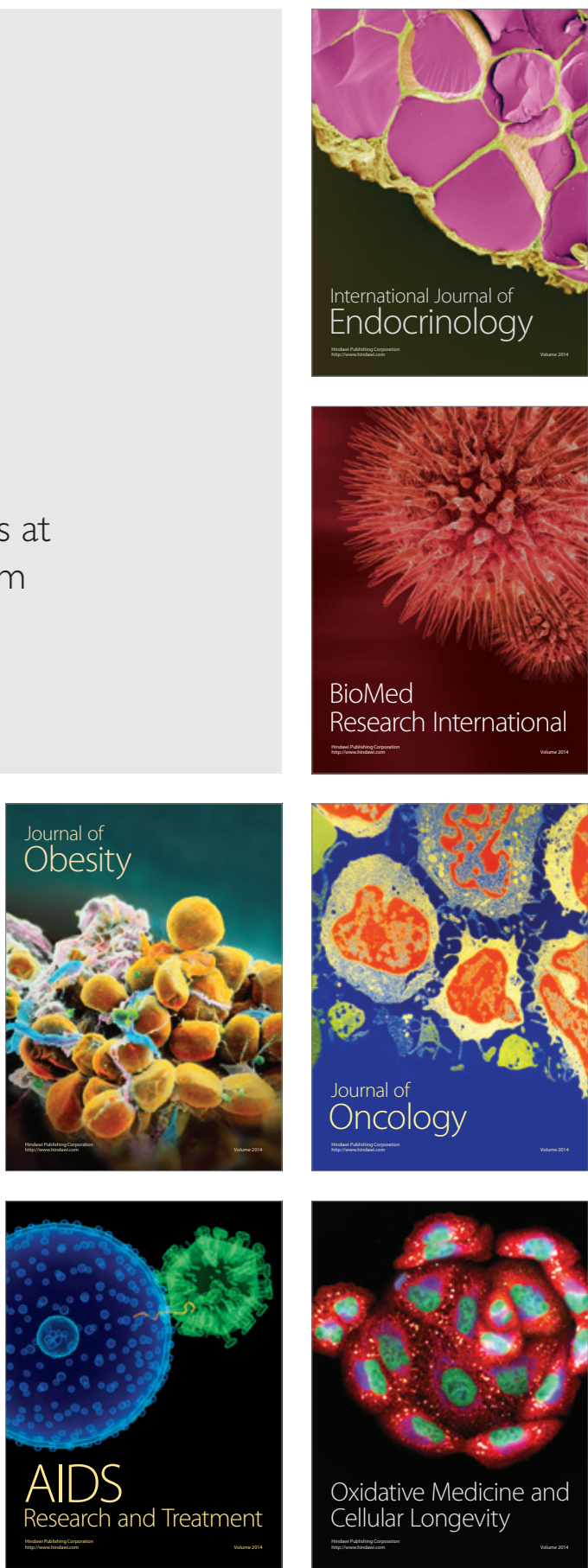